ARTIGO

\title{
A RESOLUÇÃO DE PROBLEMAS NO CURRÍCULO DE MATEMÁTICA DO ESTADO DE SÃO PAULO E NO CADERNO DO ALUNO
}

\author{
THE PROBLEM SOLVING IN THE SÃO PAULO MATHEMATICAL CURRICULUM \\ AND IN THE CADERNO DO ALUNO
}

\section{RESOLUCIÓN DE PROBLEMAS EN EL CURRÍCULO MATEMÁTICO DE SÃO PAULO Y EN EL CADERNO DO ALUNO}

\author{
Daniela Zanardo Rossetto \\ Universidade Estadual Paulista - Brasil \\ Inocêncio Fernandes Balieiro Filho \\ Universidade Estadual Paulista - Brasil
}

\begin{abstract}
Resumo: Neste artigo é realizada uma análise sobre o tratamento dado à resolução de problemas no Currículo de Matemática do Estado de São Paulo e no material Caderno do Aluno, para o Ensino Médio. Para isso, numa abordagem qualitativa de pesquisa, foi utilizada a metodologia de Análise Documental. Para a análise do Caderno do Aluno também consideramos o documento Matriz de Avaliação Processual que especifica os conteúdos, as competências e habilidades que devem ser desenvolvidas ao longo dos bimestres, dando destaque para as que deverão orientar a elaboração das provas de Avaliação de Aprendizagem. Os resultados obtidos mostram que embora o Currículo enfatize a importância do desenvolvimento da capacidade de resolver problemas e dê destaque a problematização como uma boa estratégia de ensino para o desenvolvimento de determinadas competências pessoais, o material Caderno do Aluno apresenta poucos problemas e, consequentemente, oferece poucas oportunidades que de fato possibilitem o desenvolvimento da capacidade de inquirir e de perguntar.
\end{abstract}

Palavras chave: Ensino de matemática; Resolução de problemas; Currículo.

\begin{abstract}
In this paper we stablished an analysis about the treatment given to Problem Solving in the Mathematics Curriculum of the State of São Paulo and the material Caderno do Aluno, in High School. For the analysis of the Curriculum we used the methodology of Documentary Analysis and for the analysis of the Caderno do Aluno we performed a survey of the problems that compose the material and then we used the Matrix of Process Assessment to establish a qualitative analysis on the given approach to solving problems in this material. The data obtained show that, although the São Paulo State Curriculum emphasizes the importance of the development of problem solving skills and emphasizes problematization as a good teaching strategy for the development of certain personal competences, the Caderno do Aluno material presents few problems and, consequently, offers few opportunities that in fact allow the development of the capacity to inquire and ask.
\end{abstract}

Keywords: Mathematics teaching; Problem solving; Curriculum. 
Resumen: El objetivo de este trabajo es analizar y discutir cuál es el tratamiento dado a la resolución de problemas en el Currículo de Matemáticas del Estado de São Paulo y en el material Caderno do Aluno, para la Enseñanza Media. Para el análisis del Currículo se utilizó la Análisis Documental y para el análisis del Caderno do Aluno se realizó un levantamiento de los problemas que componen el material y luego utilizamos la Matriz de Evaluación Procesal para establecer un análisis cualitativo sobre el abordaje dado a la resolución de problemas en este material. Los datos obtenidos muestran que aunque el Currículo enfatiza el desarrollo de la capacidad de resolver problemas y destaque la problematización como una buena estrategia de enseñanza para el desarrollo de determinadas competencias personales, el material Caderno do Aluno presenta pocos problemas y, por consiguiente, ofrece pocas oportunidades que de hecho posibiliten el desarrollo de la capacidad de preguntar y de preguntar.

Palabras clave: Enseñanza de matemáticas; Solución de problemas; Plan de estudios.

\section{Introdução}

O presente artigo apresenta uma discussão sobre o tratamento dado à resolução de problemas no Currículo de Matemática das séries do Ensino Médio do Estado de São Paulo e no material Caderno do Aluno.

Para isso, numa abordagem de pesquisa qualitativa, foi utilizada a análise documental (PIMENTEL, 2001). O Currículo e a Matriz de Avaliação Processual foram obtidos no sítio eletrônico da Secretaria de Educação do Estado de São Paulo. Já os volumes do material Caderno do Aluno foram disponibilizados pela Secretaria após solicitarmos, via mensagem eletrônica, o acesso aos materiais. Todos os documentos foram organizados e salvos em arquivos eletrônicos. Em seguida, passamos a explorar os documentos, tendo em mente o objetivo proposto, de forma que os dados pudessem ser codificados e interpretados, com o intuito de encontrarmos respostas para nossa questão.

O objetivo de analisar e discutir os documentos que compõem o Currículo de Matemática do Estado de São Paulo para o Ensino Médio busca trazer a luz elementos para uma reflexão e discussão que possam promover mudanças, especialmente, ao considerarmos que a aprovação da Base Nacional Comum Curricular do Ensino Médio deverá promover alterações no Currículo de Matemática do Estado de São Paulo e, em consequência, nos materiais utilizados pelos alunos e docentes.

A motivação da pesquisa aqui apresentada foi o desempenho dos alunos do Ensino Médio do Estado de São Paulo nas avaliações nacionais, como SAEB (Sistema de Avaliação da Educação Básica) e SARESP (Sistema de Avaliação de Rendimento Escolar do Estado de São Paulo) e na avaliação internacional PISA (Programme for International Student Assessment), em que um dos principais problemas apontados é a dificuldade dos alunos em 
interpretar e resolver problemas de Matemática (RODRIGUES, 2014; SANTADE, 2015; CARNOY et al., 2015; BRASIL, 2016; BERTAGNA, POLATO e MELLO, 2018; SPIELMANN e CIANI, 2018). Nesse cenário, é relevante compreender a forma como a resolução de problemas é tratada em sala de aula e, para isso, é necessário entendermos a forma como essa abordagem é explorada no Currículo e no material didático utilizado em sala de aula pelos alunos e professores.

Ainda que outros fatores possam influenciar a forma como a resolução de problemas é desenvolvida em sala de aula, por exemplo, crenças e visões dos professores, da equipe de coordenação e direção, conhecimentos prévios dos alunos, aspectos sociais, políticos e culturais dos alunos da turma e da escola, influência dos pais e da família, entre outros, consideramos que o papel do professor e, em especial, dos materiais que são utilizados por ele têm alcance abrangente. Turíbio e Silva (2017), por exemplo, ao discutirem a influência do livro didático na prática docente, constataram que os docentes investigados por eles seguiam a mesma sequência dos conteúdos apresentados no livro e, dessa forma, o livro didático acabava determinando o currículo e a prática pedagógica dos professores. No caso específico do Estado de São Paulo, nas escolas públicas, o Currículo é materializado por meio do Caderno do Aluno e, desse modo, podemos conjecturar que as concepções desse material têm influência na visão dos professores.

Nas discussões aqui apresentadas, partimos do pressuposto de que a resolução de problemas é uma relevante estratégia didática a ser considerada nos processos de ensino e de aprendizagem de Matemática e consideramos a influência do Currículo do Estado de São Paulo no ensino de milhares de estudantes da rede pública estadual. As nossas reflexões sobre o que compreendemos como um problema e como resolução de problemas, após cuidadosa revisão teórica e análise do que é preconizado no Currículo, direcionaram nossa análise para os problemas que são apresentados no Caderno do Aluno. Também utilizamos o documento Matriz de Avaliação Processual para compreender quais conteúdos, competências e habilidades são enfatizadas na orientação para a elaboração das provas da Avaliação da Aprendizagem em Processo, que devem ser aplicadas bimestralmente para os componentes de Língua Portuguesa e de Matemática.

\section{Fundamentação teórica sobre resolução de problemas}

Em nossa experiência como alunos e também como professores, percebemos que nos processos de ensino e de aprendizagem da Matemática, as metodologias que têm como base a 
fixação de regras e fórmulas acabam sendo priorizadas pelos professores e o modelo tradicional de ensino é eleito por muitos docentes na condução do processo de ensino dessa disciplina. De fato, a formalização, isto é, a concretização de um determinado conhecimento de acordo com regras ou convenções, é um aspecto importante na aprendizagem. No entanto, segundo Coelho (2005), a formalização, embora seja indispensável na Matemática, fazendo parte de sua linguagem por possibilitar uma comunicação universal, não deve ser apresentada aos alunos como um passo inicial nos processos de ensino e aprendizagem dessa ciência. Antes de decorar fórmulas e regras, o aluno precisa compreender o conceito para que o conhecimento adquira sentido para ele, ou seja, a sistematização formal deve ser introduzida após o entendimento do conteúdo que se quer ensinar.

Quando a Matemática é ensinada somente a partir da memorização de conceitos e procedimentos, por diversas ocasiões, ela se torna incompreensível e abstrata demais para os alunos. Além disso, o rigor matemático, quando imposto antes da superação das dificuldades e da compreensão de um novo conteúdo que está sendo introduzido, pode não promover uma aprendizagem satisfatória.

Para que haja uma aprendizagem significativa dos conteúdos é preciso que os alunos participem ativamente do processo de construção de novos conhecimentos (SANTAROSA, 2016). Por isso, ao invés de centralizar o ensino somente em regras que devem ser memorizadas, as atividades trabalhadas em sala de aula devem oferecer possibilidades que favoreçam o desenvolvimento do pensamento matemático do estudante. Assim, as atividades que contemplam a resolução de problemas se apresentam como uma boa opção de tarefa a ser trabalhada nos processos de ensino e aprendizagem de Matemática, pois, além de permitir que os alunos participem ativamente da construção de conhecimentos matemáticos, contribuindo com suas ideias, também tem potencial para despertar o interesse dos aprendizes (ONUCHIC, 2014).

Uma das concepções que se tem sobre resolução de problemas é que essa é uma metodologia de ensino em que a aprendizagem ocorre por meio do uso de situações-problema. De acordo com Nickerson (2011), na literatura de Matemática e Educação Matemática, um problema pode ter um significado mais abrangente, referindo-se a qualquer questão matemática, porém, quando pesquisadores e educadores enfatizam que o ensino de Matemática deve privilegiar a resolução de problemas, eles se referem a problemas cuja solução demanda algum raciocínio criativo ou crítico, ou seja, a resolução do problema deve ir além do uso da memória e da aplicação mecânica de fórmulas e algoritmos já aprendidos. 
Segundo Miranda (2015), alguns autores têm apresentado pesquisas ao longo dos anos mostrando a resolução de problemas como uma metodologia de ensino capaz de potencializar os processos de ensino e de aprendizagem nas aulas de Matemática, fortalecendo a construção dos conhecimentos pelos estudantes. Nessa perspectiva, um problema matemático é uma situação que demanda uma sequência de ações para se obter um resultado, o que significa que a solução não está disponível de início, mas é possível construí-la.

Durante o desenvolvimento do ensino de Matemática é comum a utilização de exercícios de fixação, então é importante entendermos a diferença entre um problema e um exercício. Segundo Nickerson (2011),

No início do século vinte, Morton (1927) fez uma distinção entre problemas e exemplos, ou o que poderia ser denominado de exercícios. Para o último, os procedimentos que levariam à solução foram fornecidos antecipadamente, ao passo que no primeiro não o eram. Em uma meta-análise de estudos de resolução de problemas matemáticos, Hembree e Marsh (1993) dividiram os problemas estudados em dois tipos principais: problemas "padrão (palavra ou história) que exigem tradução de declarações verbais em operações matemáticas; e processos ou problemas em aberto para os quais os solucionadores não possuem procedimentos de rotina para encontrar uma resposta". (...) O que é um problema de bona fide [boa-fé] para uma pessoa pode não ser para outra, ou ainda para o mesmo indivíduo em um momento diferente. As atividades que envolvam adição e subtração podem constituir problemas reais para os alunos que estão começando a aprender as regras e procedimentos relevantes da aritmética básica (...), ao passo que elas não seriam problemáticas no mesmo sentido para estudantes mais velhos que dominassem essa área da Matemática. O que pode constituir um problema muito desafiador até mesmo para um aluno avançado em matemática superior pode ser um exercício normal para um especialista da área. (NICKERSON, 2011, p. 424).

Assim, entendemos que um problema matemático tem como principal característica o fato de que a sua solução não depende apenas da aplicação súbita de regras ou fórmulas que já foram expostas pelo professor, diferentemente do exercício, em que a sua própria estrutura já deixa claro quais procedimentos devem ser utilizados durante a resolução.

Além disso, para que se possa chegar à solução correta de um problema é preciso que haja uma reflexão profunda em torno do contexto estabelecido e dos dados apresentados. Somente após essa análise será possível elaborar estratégias para resolvê-lo ou aplicar procedimentos e fórmulas que foram expostas anteriormente. Em síntese, para que uma situação seja considerada de fato um problema, ela deve ser apresentada como algo novo, em que as informações necessárias para sua resolução não estejam explícitas, oferecendo condições para que se possa investigar, questionar e elaborar novas ideias. 
Podemos constatar que a resolução de problemas possibilita a participação ativa do aluno no processo de construção de novos conhecimentos matemáticos, pois ele não só pode, como deve, utilizar os conhecimentos que já possui para elaborar novas ideias. Ele precisa refletir, questionar, levantar hipóteses e articular estratégias.

Muitos estudos (COELHO, 2005; ALVARENGA, 2008; ONUCHIC, 2014) enfatizam que a utilização da resolução de problemas no ensino de Matemática, além de proporcionar a aprendizagem de conceitos e habilidades, é uma estratégia didática importante para o desenvolvimento do raciocínio lógico dos alunos e das habilidades de argumentar, comunicar ideias, tomar decisões, investigar e compreender situações. Ela oferece ao educando possibilidades de desenvolver sua autonomia e a capacidade de persistência.

Como esse tipo de atividade permite que os alunos utilizem os conhecimentos que já possuem, também oferece a oportunidade de ampliá-los. É um método favorável para que conheçam aplicações de Matemática em situações que para eles possam ser mais significativas. Além disso, "essa opção traz implícita a convicção de que o conhecimento matemático ganha significado quando os alunos têm situações desafiadoras para resolver e trabalham para desenvolver estratégias de resolução" (BRASIL, 1988, p. 39).

Por se tratar de situações desafiadoras, os problemas têm potencial para despertar o interesse do aluno e, consequentemente, promover o seu envolvimento com a atividade. No entanto, prender a atenção dos estudantes não é uma tarefa fácil. Por isso, ao planejar essas atividades, o professor deve levar em conta que cada turma possui suas particularidades.

Para Vieira (2009) é importante que os professores tenham a oportunidade de problematizar suas concepções acerca do papel dos recursos utilizados por eles, que tomem consciência, façam questionamentos e reflitam sobre as suas intencionalidades e que avaliem a eficácia didática desses recursos, ou seja, a sua funcionalidade como meio facilitador do processo de ensino e de aprendizagem.

Dessa forma, a escolha adequada dos problemas a serem trabalhados depende de uma reflexão ampla e aprofundada em torno dos objetivos propostos em seu planejamento. Além disso, ao elaborar a atividade, é necessário que o educador leve em consideração o nível de desenvolvimento cognitivo de seus alunos, para que possa fazer essa escolha de maneira apropriada, contribuindo para que os alunos desenvolvam uma atitude favorável diante da resolução de problemas.

É importante que o educador tenha consciência de que os alunos precisam de sua ajuda. No entanto, ela precisa ser dosada. De fato, "a ajuda de um professor deve ser suficiente e necessária" (ALFARO, 2006, p.3). A falta de auxílio poderá levar o aluno a desistir de buscar 
a solução, especialmente, nas situações em que aquele tenha sérias dificuldades, e o excesso poderá tornar o trabalho muito fácil, o que acabaria com o espírito desafiador desse tipo de atividade.

Apesar de muitos educadores reconhecerem a importância da utilização de resolução de problemas no ensino de Matemática, em diversas ocasiões no contexto de sala de aula, os problemas acabam sendo utilizados de forma semelhante ao uso dos exercícios de fixação, ou seja, para praticar o que já foi ensinado. É comum que o aprendiz se sinta obrigado a utilizar os mesmos procedimentos que o professor empregou para elaborar seu plano de resolução, o que, em consequência, inibe a autonomia e a criatividade do aluno. Outro fator importante a ser levado em consideração, de acordo com Smole e Diniz (2007), é que, ao se deparar com um problema em que o indivíduo não identifica o modelo a ser seguido, os únicos caminhos restantes são desistir ou esperar a resposta de um colega ou até mesmo do professor.

Esse tipo de situação acaba levando os alunos a construir uma concepção equivocada sobre o processo de resolução de um problema. Normalmente, ficam com a ideia de que existe sempre uma única solução para a situação-problema proposta e ela somente estará correta se for resolvida como o professor ensinou, utilizando os mesmos passos, as mesmas regras e fórmulas. No entanto, além de existirem muitas maneiras diferentes para chegar à solução correta de um problema, é importante salientar que resolver não significa, necessariamente, encontrar uma única resposta. Uma das características de uma situação-problema, é que ela pode ter uma, mais de uma ou nenhuma solução.

Em relação às atividades de resolução de problemas no contexto escolar, Marco (2004) destaca que elas devem ser realizadas de forma que possam propiciar aos alunos situações interessantes, que desafiem sua curiosidade e que possuam elementos dinâmicos da vida, para que o sujeito possa vivenciar a tensão criativa, a reordenação lógica, a construção e reconstrução dos conceitos por meio delas. A autora também salienta que o professor, como mediador do trabalho, deve levar os alunos a retomar a situação analisada e resolvida, deixando-os desfrutar da satisfação da criação da resolução da situação problema proposta.

De acordo com Balieiro (2017), Polya discutiu a utilização de procedimentos heurísticos com o intuito de resolver problemas. A heurística é o processo pelo qual qualquer pessoa, ao tentar resolver diversos problemas cotidianos ou não, tenta várias abordagens para encontrar a solução ou não desses problemas propostos. Além disso, é importante lembrar que um modelo heurístico, em seu processo, envolve vários procedimentos cognitivos de raciocínio (analogia, análise, síntese, indução, dedução, etc.) e é bastante diferente de um algoritmo, ou seja, uma sequência finita de instruções bem definidas e não ambíguas, em que cada uma das quais deve 
ser executada mecânica ou eletronicamente. De fato, quando um aluno reconhece que uma determinada estratégia algorítmica é adequada e a emprega corretamente, ele garante que a resposta para seu problema ou exercício esteja correta. Entretanto, em um modelo heurístico, os processos cognitivos de raciocínio são definidos exclusivamente como um procedimento ou roteiro para resolução de problemas em geral. Esse roteiro tem como intuito organizar os processos cognitivos, porém ele pode ser utilizado corretamente sem garantir que se obtenha uma resposta correta.

Nessa perspectiva, um problema é uma situação com que se confronta o aluno, que requer solução ou não e quando há essa solução, a estratégia para se chegar à resposta não é imediatamente conhecida. Em conformidade com essa definição de problema, podemos classificar muitos "problemas" que os professores propõem ou que aparecem em livros didáticos como "exercícios". De fato, alguns professores agrupam os "problemas" por tipos e instruem os alunos sobre como devem abordá-los para solucioná-los. Nesse contexto, os alunos são ensinados sobre como proceder para resolver esses "problemas" e que outros "problemas" semelhantes devem ser solucionados de maneira análoga, embora com números, fórmulas ou algoritmos diferentes; esses procedimentos podem levar os alunos a ter certa passividade de raciocínio. De fato, esses "problemas" são denominados "exercícios”, porque o reconhecimento do tipo de "problema" induz o aluno a adotar um procedimento ou método conhecido para encontrar a resposta correta. Assim, há uma restrição de pensamento, de raciocínio e de procedimentos heurísticos utilizados pelos alunos, já que só o que os alunos precisam fazer é reconhecer o tipo de exercício e lembrar qual abordagem foi apresentada pelo professor para resolvê-los.

\section{O Currículo de Matemática do Estado de São Paulo e a resolução de problemas}

O Currículo do Estado de São Paulo foi desenvolvido pela Secretaria de Educação Estadual, por intermédio da Coordenadoria de Gestão da Educação Básica, segundo os dados fornecidos pelo site da secretaria, no ano de 2008. Posteriormente, foi implantado em todas as escolas da rede pública estadual, nos níveis do Ciclo II do Ensino Fundamental e Ensino Médio. O material é composto pelo documento básico curricular e por um conjunto de documentos dirigidos aos professores e aos alunos: Caderno do Professor e Caderno do Aluno, que foram organizados por disciplina/série(ano)/semestre, e para cada bimestre são sugeridas quatro situações de aprendizagem. Além desses documentos voltados para os processos de ensino- 
aprendizagem das disciplinas, existe ainda um segundo conjunto de documentos voltados para a gestão do Currículo na unidade escolar, denominado Caderno do Gestor.

O documento básico curricular foi contextualizado com base nas normas estabelecidas pela LDBEN (Lei de Diretrizes e Bases da Educação Nacional), pelos DCN (Diretrizes Curriculares Nacionais) e nas recomendações dos PCN (Parâmetros Curriculares Nacionais) do Ensino Médio.

De acordo com a apresentação do Currículo do Estado de São Paulo de Matemática e suas tecnologias, o processo de criação desse conjunto de documentos teve como ponto de partida os conhecimentos e as experiências práticas acumuladas, isto é, surgiu valendo-se da recuperação, da revisão e da sistematização de documentos, publicações e diagnósticos já existentes e do levantamento e análise dos resultados de projetos ou iniciativas que já haviam sido realizados em outros momentos. Ainda, segundo a apresentação do documento, a equipe que trabalhou no seu desenvolvimento realizou um amplo levantamento do acervo documental e técnico pedagógico existente e, também, deu início a um processo de consulta a escolas e professores para identificar, sistematizar e divulgar boas práticas existentes nas escolas estaduais.

No entanto, a afirmação de que a equipe que trabalhou no desenvolvimento do Currículo consultou as escolas e os professores da rede se opõe à fala de grande parte dos educadores, visto que muitos deles alegam não terem sido consultados e nem preparados de maneira adequada para trabalhar com o material. Conforme destacado por Alvarenga (2008), a proposta curricular foi instituída sem consulta e sem uma instrução técnico-pedagógica especifica para os professores.

De acordo com Busquini (2013), embora a Secretaria da Educação do Estado de São Paulo tenha promovido, no ano de 2006, um seminário com o objetivo de debater as propostas curriculares, na ocasião da sua elaboração não houve a participação dos docentes e o que restou a esses profissionais foi a possibilidade de opinar por meio de sugestões e críticas, somente após a implantação do Currículo nas escolas.

Segundo o que preconiza o documento (SÃO PAULO, 2012), os conteúdos devem ser organizados de maneira que possibilitem o tratamento dos dados que possam se transformar em informações e, consequentemente, sirvam de base para a construção do conhecimento. Nos materiais de apoio oferecidos aos professores, busca-se apresentar cada tema de um modo especialmente significativo do ponto de vista de seu valor formativo e construir uma articulação entre esses temas para que, assim, se auxiliem mutuamente, ao mesmo tempo em que propiciem conexões com as outras disciplinas. 


\section{O que o Currículo diz sobre resolução de problemas?}

Logo no início da apresentação do documento curricular, a capacidade de resolver problemas, assim como a de trabalhar em grupos, continuar aprendendo e agir de modo cooperativo, são características cognitivas destacadas por seus desenvolvedores por serem cada vez mais valorizadas pela sociedade contemporânea. Em outra parte do texto, habilidades como a tomada de decisão em contextos de resolução de problemas são destacadas por favorecer a aprendizagem de determinadas competências.

De acordo com o documento, na exploração de cada centro de interesse, uma estratégia que pode ser bem produtiva é a problematização, a formulação e o equacionamento de problemas, a tradução de perguntas formuladas em diferentes contextos em equações a serem resolvidas, pois, muito além de construir procedimentos para usar os dados e com eles chegar às respostas pedidas, o processo de resolução de um problema, constitui um poderoso exercício da capacidade de inquirir, de perguntar. Além disso, a problematização é uma das ideias fundamentais presentes em determinados conteúdos e que deve ser trabalhada para que seja possível construir uma ponte que conduza dos conteúdos às competências pessoais.

Apesar de o Currículo dar destaque para a resolução de problemas, ainda que o Currículo não use esse termo, mas sim "problematizar" e "problematização", não há uma indicação de como o professor poderia desenvolver esse trabalho em sala de aula. Ao falar de problematização, o Currículo se baseia nos PCN que, por sua vez, se baseiam no National Council of Teachers of Mathematics (NCTM). No caso do NCTM, vale destacar que houve a elaboração de subsídios para auxiliar o professor. De acordo com Morais e Onuchic (2014), em um dos capítulos do livro chamado Novas Direções para Matemática da Escola Elementar, livro de 1989 do NCTM, Schroeder e Lester afirmam que muitos materiais foram produzidos para a sala de aula durante a década de 1980 e que essa produção estava ajudando muitos educadores a fazer da resolução de problemas o foco do seu trabalho.

A Matemática é um componente básico dos currículos escolares. Ela é apresentada como um sistema primário de expressão assim como a língua materna, com a qual interage continuamente. No Estado de São Paulo, nas propostas curriculares elaboradas a partir de 1984, e que foram substituídas pelo Currículo atual, a Matemática sempre foi considerada uma área específica.

O Currículo apresenta três pares complementares de competências que constituem três eixos norteadores da ação educacional e que foram fundamentados nas ideias gerais 
apresentadas na formulação do ENEM (Exame Nacional do Ensino Médio). São eles: o eixo expressão/compreensão; o eixo argumentação/decisão; o eixo contextualização/abstração.

No eixo expressão/compreensão a Matemática compõe um par complementar como meio de expressão e de compreensão da realidade assim como a Língua Portuguesa. Já no eixo argumentação/decisão, na construção do pensamento lógico, seja ele indutivo ou dedutivo, a Matemática e a língua materna partilham fraternalmente a função de desenvolvimento do raciocínio. No terceiro eixo, contextualização/abstração, a Matemática é adequada, ou até mesmo privilegiada, para se aprender a lidar com os elementos do par concreto/abstrato.

De acordo com as ideias expressas no Currículo, os conteúdos estudados na disciplina Matemática são considerados um meio para o desenvolvimento de competências com a capacidade de expressão pessoal, de compreensão de fenômenos, de argumentação consistente, de tomada de decisões, de problematização e enraizamento dos conteúdos estudados em diferentes contextos e de imaginação de situações novas.

Segundo o documento curricular (SÃO PAULO, 2012), a estratégia utilizada na construção dos Cadernos do Professor, tendo em vista o desenvolvimento das competências, foi a identificação e a exploração das ideias fundamentais de cada tema e a ideia central que serve como base para as ações educacionais em todas as disciplinas é a transformação de informação em conhecimento, isto é, em cada conteúdo devem ser identificadas as ideias fundamentais a serem exploradas. Em Matemática, alguns exemplos de ideias essenciais são proporcionalidade, equivalência, ordem, aproximação, problematização, otimização, entre outras.

A lista de conteúdos a serem trabalhados é constituída pelos assuntos usuais que aparecem nos diversos programas e materiais didáticos já existentes e, no caso de Matemática, estão divididos em três grandes blocos temáticos, tanto no Ensino Fundamental quanto no Ensino Médio, que são: Números, Geometria e Relações. As interconexões entre os três blocos temáticos ocorrem quase sempre de forma bastante natural.

A análise do Currículo de Matemática do Estado de São Paulo mostra que há uma ênfase em apontar que as atividades desenvolvidas com os alunos em sala de aula devem envolver o trabalho com a resolução de problemas.

Na exploração de cada centro de interesse, uma estratégia muito fecunda é a via da problematização, da formulação e do equacionamento de problemas, da tradução de perguntas formuladas em diferentes contextos em equações a serem resolvidas. Muito além dos problemas estereotipados em que a solução consiste em construir procedimentos para usar os dados e com eles chegar aos pedidos, os problemas constituem, em cada situação concreta, um poderoso 
exercício da capacidade de inquirir, de perguntar (SÃO PAULO, 2011, p. 46, grifo nosso).

No Currículo é enfatizada a ideia de que os problemas que devem ser usados para promover a estratégia de problematização não podem envolver a simples aplicação de processos já fornecidos, porém devem promover a capacidade de inquirir e perguntar do aluno, isto é, de promover uma reflexão sobre os dados apresentados e sobre a situação proposta.

Problematizar é explicitar perguntas bem formuladas a respeito de determinado tema. E, uma vez formuladas as perguntas, para respondê-las, é necessário discernir o que é relevante e o que não é relevante no caminho para a resposta. A competência na distinção entre a informação essencial e a supérflua para a obtenção da resposta é absolutamente decisiva e deve ser permanentemente desenvolvida. Convém registrar que, na escola, os alunos costumam ser mais induzidos a dar respostas do que a formular perguntas. Todas as caricaturas da escola - algumas bem grotescas - resumem a atividade do professor à mera formulação de questões a serem respondidas pelos alunos. O desenvolvimento da inteligência, no entanto, está diretamente relacionado com a capacidade de fazer as perguntas pertinentes ao tema, as perguntas que realmente nos interessam, do que a fornecer as respostas certas a perguntas oriundas de interesses que não são nossos, ou que não fomos levados a fazer nossos. (SÃO PAULO, 2011, p. 47).

Quando o aluno é confrontado por questões bem formuladas a respeito de um determinado tema, ele precisa discernir sobre o que é relevante e o que não é relevante para encontrar a resposta. Entende-se que as questões bem formuladas, segundo a visão expressa no Currículo, são aquelas que levam o aluno a pensar sobre o que está sendo perguntado, a refletir sobre os possíveis caminhos que podem levá-lo à solução correta e que favoreçam o desenvolvimento da capacidade de tomar decisões, ou seja, questões em que o meio para se chegar à solução não seja dado de forma clara no enunciado, já que o desenvolvimento da competência relativa a essa distinção é importante para formação dos alunos.

\section{Sobre a Matriz de Avaliação Processual}

No documento Matriz de Avaliação Processual - Matemática - estão definidas as matrizes de referência para as avaliações ao longo dos processos de ensino-aprendizagem de todos os componentes curriculares dessa disciplina. Elas especificam os conteúdos, as competências e habilidades que devem ser desenvolvidas ao longo dos bimestres, dando destaque para as que deverão orientar a elaboração das provas da Avaliação da Aprendizagem em Processo, que devem ser aplicadas bimestralmente para os componentes de Língua Portuguesa e de Matemática. 
Analisando o documento, foi possível observar que a resolução de problemas como habilidade a ser desenvolvida pelos alunos está muito mais presente nas atividades das séries do Ensino Fundamental, fazendo parte não só da lista de expectativas de aprendizagem, como também da lista de conteúdos a serem ensinados, especialmente nos níveis iniciais. É possível constatar que conforme o nível de ensino vai avançando, a resolução de problemas vai perdendo cada vez mais espaço entre os conteúdos listados e as expectativas de aprendizagem e habilidades que devem ser desenvolvidas, a ponto de, nas matrizes referentes às séries do Ensino Médio, não aparecer, em qualquer uma delas, o termo resolução de problemas entre os conteúdos listados.

Como o foco da pesquisa é analisar o tratamento dado à de resolução de problemas no Currículo e no Caderno do Aluno, procuramos analisar se existem referências a esse tema dentre conteúdos, competências e habilidades que estão previstos como meta de ensino e de aprendizagem no material em questão e, com base nisso, cruzamos os dados encontrados na Matriz de Avaliação Processual - Matemática com os dados encontrados nos dois volumes do Caderno do Aluno de cada uma das séries do Ensino Médio.

\section{A resolução de problemas no material Caderno do Aluno de Matemática do Ensino Médio}

Entendemos que para se alcançar o que está proposto no Currículo sobre a resolução de problemas (problematização), o material Caderno do Aluno deve fornecer "bons" problemas para serem trabalhados em sala de aula. Não é nossa intenção discutir se o Caderno deve ter mais ou menos problemas ou afirmar que a inclusão de mais problemas iria promover o uso da resolução de problemas em sala de aula, mas sim analisar se o Caderno é um subsídio adequado para o desenvolvimento do que o Currículo do Estado propõe em relação ao uso da resolução de problemas em sala de aula, considerando as competências e habilidades que o Currículo preconiza para a Matemática.

Com essa análise queremos responder a questão: Como a resolução de problemas é apresentada (tratada) no Caderno do Aluno - Matemática, do Ensino Médio do Estado de São Paulo? Para realizar a análise aqui exposta, consideramos o que o Currículo do Estado de São Paulo diz sobre o trabalho com problemas em sala de aula.

Convém salientar que a resolução de problemas, enquanto abordagem de ensino, de aprendizagem e de avaliação da Matemática, não se resume à escolha de bons problemas para serem desenvolvidos em sala de aula, mas depende também da forma como o professor media o processo, visto que, dependendo da forma como a atividade for conduzida, uma questão, com 
grande potencial para ser um problema para os alunos, deixa de ser, se o seu caráter desafiador não for devidamente resguardado.

Entretanto, apesar do Currículo incentivar a autonomia do professor no planejamento de suas aulas, o Caderno do Aluno é de uso obrigatório. Todos os alunos da rede estadual recebem o material Caderno do Aluno, todos os professores recebem o Caderno Professor e as questões do SARESP são elaboradas com base nas questões do Caderno do Aluno. Isso acaba limitando a autonomia do professor.

Nesse contexto, nossa análise teve o objetivo de refletir se no Caderno do Aluno podemos encontrar problemas que possibilitem o desenvolvimento, em sala de aula, da atividade de resolução de problemas, conforme o que está preconizado no Currículo.

Iniciamos o estudo do Caderno do Aluno com um levantamento dos problemas existentes nesse material para depois fazermos uma análise com o intuito de verificar quais dos problemas propostos tinham potencial para serem usados na perspectiva da resolução de problemas apontada pelo Currículo.

Tendo em mente as discussões apresentadas no referencial teórico e a visão de problemas apresentada pelo Currículo, classificamos como problemas as atividades cuja solução não dependia apenas da aplicação imediata de regras ou fórmulas que já foram expostas pelo professor, mas sim de uma reflexão mais aprofundada em torno do contexto estabelecido e dos dados apresentados, ou seja, somente após essa reflexão seria possível elaborar estratégias para resolver o problema proposto. Assim, para que uma situação seja considerada de fato um problema, ela deve ser apresentada como algo novo para o aluno, em que as informações necessárias para sua resolução não estejam explícitas, oferecendo condições para que se possa investigar, questionar e elaborar novas ideias, de acordo com o que o Currículo propõe.

O Caderno do Professor apresenta as mesmas atividades que o Caderno do Aluno e, também, contém uma orientação geral sobre o material e uma descrição básica sobre alguns princípios e detalhes referentes ao trabalho com os conteúdos básicos do volume em questão. Conforme é introduzida cada situação de aprendizagem, no Caderno do Professor são apresentados os conteúdos e temas a serem trabalhados, as competências e habilidades a serem desenvolvidas, uma sugestão de estratégias, um roteiro para aplicação da situação de aprendizagem em questão e, ao final de cada uma dessas seções são apresentadas algumas considerações a respeito da avaliação. Para finalizar, o Caderno do Professor apresenta ainda orientações para recuperação e recursos para ampliar a perspectiva do professor e do aluno para compreensão do tema. Todos esses componentes que estão presentes apenas no Caderno do Professor têm como objetivo orientar o trabalho em sala de aula. 
É importante destacar que o Caderno do Professor, assim como o Caderno do Aluno, funciona como um material de apoio para a prática de ensino em sala de aula, com o intuito de cumprir os objetivos do Currículo. Porém, em alguns casos, o material não possui toda a teoria necessária para a abordagem dos assuntos trabalhados nas situações de aprendizagem, tornando-se necessária a utilização de outros materiais de apoio para o planejamento das aulas.

A leitura e a análise das sugestões de estratégias e as orientações presentes no roteiro para aplicação de cada situação de aprendizagem acabaram contribuindo e influenciando na classificação das questões, pois a maneira como a atividade é desenvolvida, interfere no caráter desafiador das questões. No caso de algumas situações de aprendizagem, as orientações recomendam ao professor a apresentação de exemplos, mesmo que no Caderno do Aluno não apareçam tais exemplos ou uma exposição dos conceitos.

\section{Os dados obtidos por meio da Análise do Caderno do Aluno}

No Ensino Médio há seis volumes do Caderno do Aluno para a disciplina de Matemática, com dois volumes para cada série. No quadro 1 estão os resultados obtidos, por meio da nossa análise, de exercícios, problemas e questões mistas (questão com alguns itens que são exercícios e alguns itens que são problemas) encontrados em cada volume.

Quadro 1

\begin{tabular}{|c|c|c|c|c|}
\hline ANO & $\begin{array}{c}\text { Caderno do } \\
\text { Aluno }\end{array}$ & Exercícios & Problemas & Questões Mistas \\
\hline \multirow{2}{*}{$1^{\circ}$ ANO } & VOLUME 1 & 93 & 21 & 12 \\
\cline { 2 - 5 } & VOLUME 2 & 45 & 12 & 5 \\
\hline \multirow{2}{*}{$2^{\circ}$ ANO } & VOLUME 1 & 69 & 13 & 2 \\
\cline { 2 - 5 } & VOLUME 2 & 62 & 42 & 10 \\
\hline \multirow{2}{*}{$3^{\circ}$ ANO } & VOLUME 1 & 75 & 0 & 0 \\
\cline { 2 - 5 } & VOLUME 2 & 67 & 6 & \multicolumn{2}{|c}{} \\
\hline
\end{tabular}

Fonte: Autores

Podemos observar que a maior parte das questões que fazem parte das atividades é composta por exercícios. Há duas situações especiais a serem destacadas: no Caderno do Aluno $-2^{\circ}$ ano do Ensino Médio - Volume 2, o número de problemas é bem próximo ao número de exercícios e se considerarmos as questões que possuem itens que são problemas e itens que são exercícios juntamente com os problemas, o número se torna mais próximo ainda. O outro caso a se destacar é o do Caderno do Aluno - $3^{\circ}$ ano do Ensino Médio - Volume 1, que não contém questão alguma que pode ser classificada como um problema em qualquer uma das oito situações de aprendizagem que compõem o volume. 
Devemos considerar que o Currículo que estamos analisando serve como pauta para o trabalho dos professores da rede pública estadual e a maioria desses educadores utiliza os materiais de apoio (Caderno do Aluno) do Currículo em suas aulas, tendo como objetivo principal cumprir as metas de aprendizagem para que os alunos tenham um bom desempenho nas avaliações propostas pela Secretaria Estadual de Educação. Desse modo, é coerente esperar que os professores busquem, por meio de suas avaliações, verificar se os alunos alcançaram as metas previstas pelas Matrizes de Avaliação Processual, já que uma das avaliações a que os alunos serão submetidos é a Avaliação de Aprendizagem em Processo.

Espera-se que o material que é trabalhado em sala de aula esteja de acordo com o que é preconizado no Currículo de Matemática do Estado de São Paulo, ou seja, espera-se que as atividades presentes no Caderno do Aluno sejam adequadas para o desenvolvimento das habilidades e competências que foram destacadas como metas de ensino do Currículo.

Ao comparar os dados encontrados na Matriz de Avaliação Processual - Matemática com os dados dos dois volumes do Caderno do Aluno de cada uma das séries do Ensino Médio encontramos algumas inconsistências entre o que é proposto na Matriz e o que é proposto no Caderno do Aluno em relação à resolução de problemas. Descrevemos aqui os casos em que as divergências entre os dados da Matriz e do Caderno do Aluno são mais acentuadas, isto é, os casos em que a Matriz prevê o desenvolvimento da habilidade de resolver problemas, mas o Caderno do Aluno não propõe problema algum, mas sim, somente exercícios.

No $3^{\circ}$ bimestre do $1^{\circ}$ ano do Ensino Médio, a Matriz de Avaliação Processual determina que, durante o desenvolvimento Situação de Aprendizagem 1: As potências e o crescimento/decrescimento exponencial: A função exponencial, os alunos devem enfrentar e resolver situações-problema envolvendo expoentes e funções exponenciais, além de expressar e modelar diversos fenômenos naturais envolvendo potências, compreendendo-os nos diversos contextos em que eles surgem. No entanto, das questões que fazem parte dessa situação de aprendizagem, apenas uma pode ser classificada como problema.

O mesmo ocorre para as seguintes Situações de Aprendizagem: no $1^{\circ}$ bimestre do $2^{\circ}$ ano do Ensino Médio, na Situação de Aprendizagem 2: A periodicidade e o modelo da circunferência trigonométrica; no $1^{\circ}$ bimestre do $2^{\circ}$ ano, na Situação de Aprendizagem 4: Equações trigonométricas; no $1^{\circ}$ bimestre do $3^{\circ}$ ano, na Situação de Aprendizagem 1: A geometria e o método das coordenadas e na Situação de Aprendizagem 2: A reta, a inclinação constante e a proporcionalidade, na Situação de Aprendizagem 3: Problemas lineares máximos e mínimos e na Situação de Aprendizagem 4: Circunferências e cônicas: significados, equações e aplicações; no $2^{\circ}$ bimestre do $3^{\circ}$ ano, na Situação de Aprendizagem 5: A equação 
de $3^{\circ}$ grau e o aparecimento natural dos números complexos, na Situação de Aprendizagem 7: Equações e polinômios: divisão por x-k e redução do grau da equação; no $4^{\circ}$ bimestre do $3^{\circ}$ ano, na Situação de Aprendizagem 5: A apresentação de dados estatísticos: gráficos e tabelas e na Situação de Aprendizagem 6: Média aritmética e dispersão.

\section{Resultados da análise: potencialidades e fragilidades do material Caderno do Aluno}

A partir do cruzamento dos dados da análise quantitativa do Caderno do Aluno com os dados das Matrizes de Avaliação Processual, constatamos que existem algumas divergências entre os pressupostos do documento curricular e algumas atividades propostas do Caderno do Aluno. Em algumas situações de aprendizagem, em que uma das metas era o desenvolvimento da capacidade de resolver problemas relativos a um determinado assunto, não encontramos problemas no Caderno do Aluno que se enquadrassem na concepção que adotamos com referência e que estivessem de acordo com o que o documento curricular prevê em relação à problematização.

Conforme relatamos anteriormente, o Caderno do Aluno possui muito mais questões com potencial para serem trabalhadas como exercícios do que como problemas. Além disso, em algumas situações de aprendizagem não há problemas que estejam de acordo com o que o próprio documento curricular prevê em relação à problematização. Desta forma, entendemos que o Caderno do Aluno oferece poucas oportunidades de atividades que propiciem o desenvolvimento dos processos de ensino e aprendizagem dos conteúdos por meio da problematização.

O desenvolvimento de um trabalho pautado na resolução de problemas, de acordo com os pressupostos do Currículo, poderia ser conduzido de forma mais adequada mediante a utilização de atividades de outros materiais didáticos que oferecessem propostas que transcendessem as que são apresentadas no Caderno do Aluno, com o intuito de suprir as deficiências do material analisado e proporcionar diferentes possibilidades de enfrentamento de situações problemas que ofereçam a oportunidade do desenvolvimento das capacidades pessoais que podem ser favorecidas por meio da problematização.

Um dos pontos positivos que o material traz é o estabelecimento de uma relação entre contextos vivenciados na vida real e o conteúdo matemático que será trabalhado. Em quase todas as situações em que um novo assunto vai ser introduzido, utiliza-se como recurso algum texto que fale sobre esse assunto, que seja referente à sua utilização no dia a dia, sua relação com a tecnologia, sua história, dentre outras formas de abordagem. Durante o desenvolvimento 
da situação de aprendizagem que trabalha com matrizes, no volume 1 do Caderno do Aluno do $2^{\circ}$ ano do Ensino Médio, o material traz textos sobre resolução de imagens e sobre o princípio da tomografia, por exemplo.

Em relação aos pontos negativos, em algumas situações de aprendizagem, o material propõe a realização de alguns experimentos e jogos. No entanto, nem sempre os materiais necessários para a realização desse tipo de atividade em sala de aula são fornecidos. Desta forma, muitos professores podem acabar 'pulando' esse tipo de atividade por não ter conseguido o material necessário para todos os alunos realizarem a tarefa.

Outra observação que fazemos está relacionada aos problemas propostos pelo Caderno do Aluno. Praticamente em todas as situações de aprendizagem que possuem problemas, eles quase sempre aparecem entre as questões finais da seção. Antes são trabalhados os exercícios e, assim, podemos imaginar que também são expostos os conceitos e ensinamentos a respeito do tema tratado, visto que, para resolver um exercício o aluno precisa conhecer os procedimentos, fórmulas e regras que o levariam a encontrar a solução exata. Desta forma, o problema não é utilizado como ponto de partida, permitindo que os alunos utilizem seus conhecimentos prévios para construir suas próprias soluções e assim possam adquirir as ideias necessárias para entender de maneira significativa o conteúdo que está sendo trabalhado no momento em que ele for formalizado. Apesar de mobilizar outros conhecimentos, os problemas acabam sendo trabalhados também como uma forma de exercício, exigindo que os alunos apliquem os conteúdos desenvolvidos durante as aulas.

\section{Considerações finais}

Considerando as potencialidades do ensino de Matemática por meio da resolução de problemas, retomamos neste momento a questão: qual é o tratamento dado à resolução de problemas no Currículo de Matemática do Estado de São Paulo e no Caderno do Aluno?

Por meio da análise dos documentos, pudemos constatar que seus idealizadores deixam explícito que não existe uma imposição a respeito da forma como os professores devem trabalhar os conteúdos em sala de aula. Partindo do pressuposto de que somente os educadores possuem o conhecimento necessário sobre suas turmas para decidir como irá planejar suas aulas, cabe a cada um deles decidir como e com que grau de profundidade deverá desenvolver os conteúdos sugeridos pelo Currículo. Dessa forma, o Currículo não aponta qual metodologia de ensino deve ser utilizada nos processos de ensino aprendizagem dos conteúdos matemáticos. O que encontramos no documento curricular foram apenas algumas considerações a respeito da 
utilização de algumas metodologias de ensino no trabalho desenvolvido em sala de aula no que diz respeito ao ensino dos conteúdos matemáticos. Dentre essas considerações, algumas relacionadas à resolução de problemas.

O desenvolvimento da capacidade de resolver problemas é destacado por conta de sua importância para a formação de indivíduos aptos a encarar os problemas da sociedade contemporânea, ao passo que as habilidades que são desenvolvidas por meio do trabalho em contextos de resolução de problemas são destacadas por favorecer o desenvolvimento de determinadas competências pessoais.

O Currículo tem como objetivo principal o desenvolvimento das competências pessoais e esse aspecto é enfatizado no documento. O desenvolvimento de competências pessoais, tais como a capacidade de expressão pessoal, de compreensão de fenômenos, de argumentação e de tomada de decisões, que foram citadas pelo documento, é favorecido pela realização de atividades que envolvam resolução de problemas.

Ainda sobre a análise do documento curricular, destacamos que a problematização é vista como estratégia que tem potencial para ser adequada durante a exploração dos conceitos trabalhados, por favorecer o exercício da capacidade de inquirir, perguntar e, assim, consequentemente, influenciar no desenvolvimento de algumas competências pessoais.

Para chegarmos a uma resposta para nossa questão de pesquisa, buscamos entender também como a resolução de problemas é apresentada no Caderno do Aluno - Matemática, do Ensino Médio, material que é utilizado em sala de aula para o desenvolvimento das atividades voltadas para os processos de ensino e aprendizagem dos conteúdos matemáticos.

Por meio da análise do Caderno do Aluno foi possível perceber que esse material é constituído majoritariamente por questões. Os conceitos e procedimentos a serem trabalhados raramente são expostos nas situações de aprendizagem, de modo que nas poucas ocasiões em que são expostos, aparecem inicialmente por meio de um texto abordando o assunto que será tratado, relacionando o conteúdo com questões cotidianas ou históricas, ou por meio de exemplos. Em alguns casos, os conceitos, exemplos e explicações, estão presentes apenas nas orientações para aplicação da situação de aprendizagem, que estão presentes no Caderno do Professor. Contudo, existem situações de aprendizagem em que o professor precisa recorrer a outros materiais de apoio para encontrar tais elementos.

Analisando os dados obtidos, percebemos que embora o Currículo do Estado de São Paulo enfatize a importância do desenvolvimento da capacidade de resolver problemas e dê destaque a problematização como uma boa estratégia de ensino para o desenvolvimento de determinadas competências pessoais, o Caderno do Aluno apresenta poucos problemas e, 
consequentemente, poucas oportunidades que de fato possibilitem, de forma significativa, a capacidade de inquirir e de perguntar, como defendido no Currículo em relação ao trabalho com a problematização.

As metas previstas pelas Matrizes de Avaliação Processual, que visam à aprendizagem da capacidade de resolver problemas relacionados aos assuntos que são tratados nas situações de aprendizagem, acabam dependendo de atividades compostas, em sua maioria, por questões que deixam evidente para o aluno quais os procedimentos que devem ser utilizados na busca de uma solução, distanciando-se assim do que o próprio Currículo preconiza sobre a problematização.

Nos casos em que encontramos problemas que de fato se enquadram na definição que utilizamos como referência, quase sempre, eles aparecem ao final das situações de aprendizagem ou em situações de aprendizagem que abordam um mesmo assunto que foi tratado na situação de aprendizagem anterior, sendo os problemas, nesse caso, uma espécie de aplicação contextualizada do que havia sido trabalhado anteriormente.

Considerando o uso "obrigatório" do Caderno do Aluno e as ênfases do Currículo para o desenvolvimento da capacidade de resolução de problemas por parte dos alunos, o material enviado aos professores é um subsídio que poderia apontar caminhos para o desenvolvimento de um trabalho envolvendo resolução de problemas.

No Caderno do Aluno estão presentes apenas as questões a serem trabalhadas em sala de aula e alguns textos de apoio. Contudo, algumas das orientações para aplicação das situações de aprendizagem presentes no material que é direcionado aos educadores acabam fazendo sugestões sem fornecer informações que poderiam auxiliar melhor a escolha do professor em seguir ou não o que está sendo sugerido, visto que, para fazer essa escolha, o professor precisa levar em consideração seus propósitos de ensino, tendo por base o que o documento curricular propõe. Por exemplo, ao propor o uso de problemas exemplos na abordagem de determinado assunto, deixando de enfatizar que iniciar as atividades partindo da exposição de exemplos afetaria o caráter desafiador das questões propostas nas atividades posteriores, o material acaba não deixando claro que seguir tal abordagem implica deixar de lado um trabalho voltado para problematização, que o documento curricular aponta como uma boa estratégia a ser trabalhada. Desta forma, perde-se a oportunidade de implementar as sugestões presentes no Currículo em seus materiais de apoio.

Ao se depararem com um material que oferece as atividades e as orientações de como devem ser aplicadas, a tendência é que o professor conduza as atividades conforme o que está prescrito nas sugestões do Caderno do Professor. Com o passar do tempo, esse modo de 
conduzir as atividades com base no que o Caderno do Professor propõe, certamente influencia a prática dos professores, visto que, diante da pouca preparação que os educadores da rede estadual de ensino receberam para se aprofundar num trabalho visando alcançar as metas do Currículo, conforme apontam alguns estudos que citamos no nosso texto, as orientações presentes neste material foram as que se fizeram mais presentes no dia a dia de planejamento dos professores.

Considerando que as sugestões do Currículo a respeito do desenvolvimento da capacidade de resolver problemas e o uso da problematização em prol do desenvolvimento de determinadas capacidades pessoais não são enfatizadas pelas orientações dadas no Caderno do Professor e nem nas questões presentes no Caderno do Aluno, que apresenta uma quantidade reduzida de questões que oferecem a oportunidade de uma busca pelo entendimento e a elaboração de um plano de resolução que tenha como base a tomada de decisão e no exercício da capacidade de inquirir e perguntar, concluímos que apesar do Currículo do Estado de São Paulo destacar os pontos positivos da resolução de problemas no ensino de Matemática, o material fornecido pela secretaria e destinado para o trabalho em sala de aula apresenta poucas possibilidades para o real desenvolvimento das capacidades pessoais que podem ter seu desenvolvimento favorecido por meio da problematização.

\section{REFERÊNCIAS}

ALFARO, Cristian. Las Ideas de Pólya en la Resolución de Problemas. Cuadernos De Investigación Y Formación En Educación Matemática, Costa Rica, n. 1, ano 1, p. 1-13, 2006.

ALVARENGA, Rosana Cristina Macelloni. O Raciocínio lógico e a criatividade na resolução de problemas matemáticos no ensino médio. 2008. 99 f. Dissertação (Mestrado em Educação) - Faculdade de Filosofia e Ciências, Universidade Estadual Paulista, Marília, 2008. Disponível em: http://hdl.handle.net/11449/91278. Acesso em: 20 jun. 2017

BALIEIRO FILHO, Inocêncio Fernandes. Arquimedes, Pappus, Descartes e Polya: quatro episódios da história da heurística. São Paulo: Editora Unesp Digital, 2017.

BERTAGNA, Regina Helena; POLATO, Amanda; MELLO, Liliane Ribeiro. As avaliações em larga escala e o Currículo no Estado de São Paulo: a realidade escolar desvelando as lógicas subjacentes. Currículo sem Fronteiras, v. 18, n. 1, p. 52-70, jan./abr. 2018.

BRASIL. Brasil no Pisa 2015: análises e reflexões sobre o desempenho dos estudantes brasileiros/OCDE- Organização para a Cooperação e Desenvolvimento Econômico. São Paulo: Fundação Sentinela, 2016. 
BRASIL. Ministério da Educação e do Desporto. Secretaria de Educação Fundamental. Parâmetros Curriculares Nacionais: Terceiro e Quarto ciclos: Matemática. Brasília, DF, 1998. Disponível em: http://portal.mec.gov.br/seb/ arquivos/pdf/matematica.pdf. Acesso em: 19 maio 2016.

BRASIL. Ministério da Educação. Instituto Nacional de Estudos e Pesquisas Educacionais Anísio Teixeira. ENEM: documento básico. Brasília, DF, 2002. Disponível em: http://portal.inep.gov.br/documents/186968/484421/ENEM++ Exame+Nacional+do+Ensino+M\%C3\%A9dio+documento+b\%C3\%A1sico+2002/193b6522 -cd52-4ed2-a30f-24c582ae941d?version=1.2. Acesso em: 10 mar. 2018.

BUSQUINI, João Acácio. A proposta curricular do Estado de São Paulo de 2008: discurso, participação e prática dos professores de Matemática. 2013. 235 f. Tese (Doutorado) - Faculdade de Educação, Universidade de São Paulo, São Paulo - SP. Disponível em: http://www.teses.usp.br/teses/disponiveis/48/48134/tde-02072013-133610/pt-br.php. Acesso em: 11 mar. 2018.

CARNOY, Martin; KHAVENSON, Tatiana; FONSECA, Izabel; COSTA, Leandro; MAROTTA, Luana. A educação brasileira está melhorando? Evidências do PISA e do SAEB. Cadernos de Pesquisa, v.45 n.157 p.450-485 jul./set. 2015.

COELHO, Maria Aparecida Vilela Mendonça Pinto. A Resolução de problemas: da dimensão técnica a uma dimensão problematizadora. 2005. 160 f. Dissertação (Mestrado) Faculdade de Educação, Universidade Estadual de Campinas, Campinas, 2005. Disponível em: http://www.bibliotecadigital.unicamp.br/document/?code=vtls000363607. Acesso em: 10 nov. 2016.

MARCO, Fabiana Fiorezi de. Estudo dos processos de resolução de problema mediante a construção de jogos computacionais de matemática no ensino fundamental. 2004. $140 \mathrm{f}$. Dissertação (Mestrado em Educação) - Faculdade de Educação, Universidade Estadual de Campinas, Campinas, 2004. Disponível em:

http://www.bibliotecadigital.unicamp.br/document/?code=vtls000316327. Acesso em: 30 out. 2016.

MIRANDA, Ana Sofia Macedo Szczepaniak. Resolução de problemas como metodologia de ensino: uma análise das repercussões de uma formação continuada. $2015.116 \mathrm{f}$. Dissertação (Mestrado em Educação em Ciências e Matemática) - Faculdade de Física, Pontifícia Universidade Católica do Rio Grande do Sul, Porto Alegre, 2015. Disponível em: http://repositorio.pucrs.br/dspace/bitstream/10923/7522/1/00047 3840-Texto\%2bCompleto0.pdf. Acesso em: 10 nov. 2016.

MORAIS, Rosilda Santos; ONUCHIC, Lourdes De La Rosa. Uma abordagem histórica da resolução de problemas. In: ONUCHIC, Lourdes De La Rosa. et al. (Org.). Resoluçãa de problemas: teoria e Prática. Jundiaí: Paco, 2014. p. 17-34.

NICKERSON, Raymond S. Mathematical reasoning: patterns, problems, conjectures, and proofs. New York: Taylor and Francis Group, 2011.

PIMENTEL, Alessandra. O método da análise documental: seu uso numa pesquisa historiográfica. Cadernos de Pesquisa, n. 114, p. 179-195, nov. 2001. 
RODRIGUES, Suely da Silva. Eficácia docente: um estudo com professores de matemática da rede estadual de São Paulo. Tese. 2014. 226 f. (Doutorado em Educação). Pontifícia Universidade Católica do Rio de Janeiro. Rio de Janeiro, 2014.

SANTADE, Susimara. Currículo de Matemática do Estado de São Paulo e SARESP: análise crítica. Dissertação. 2015. 110 f. (Mestrado em Educação) - Universidade do Oeste Paulista, Presidente Prudente, 2015.

SANTAROSA, Maria Cecília Pereira. Ensaio sobre a aprendizagem significativa no ensino de matemática. Aprendizagem Significativa em Revista, v. 6, n. 3, p. 57-69, 2016.

SÃO PAULO. Secretaria da Educação do Estado de São Paulo. Currículo do Estado de São Paulo. São Paulo, 2017. Disponível em: http://www.educacao.sp.gov.br/curriculo. Acesso em: 17 jun. 2017.

SMOLE, Katia; DINIZ, Maria Ignes. Ler, escrever e resolver problemas: habilidades básicas para aprender matemática. Porto Alegre: Artmed, 2007.

SPIELMANN, Rosane; CIANI, Andréia Büttner. Um olhar sobre algumas questões de matemática do exame do PISA. RPEM, Campo Mourão, Pr, v.7, n.14, p.256-273, jul.-dez. 2018.

TURÍBIO, Solange Ramos Teixeira; SILVA, Adelmo Carvalho. A influência do livro didático na prática pedagógica do professor que ensina matemática. Revista Prática Docente, v. 2, n. 2, p. 158-178, 22 dez. 2017.

VIEIRA, Celina Tenreiro. Potenciar a utilização de recursos no ensino e aprendizagem da matemática a partir da reflexão sobre a ação. REVEMAT, Florianópolis - SC, v. 4, n. 1, p.3952, 2009. Disponível em:

https://periodicos.ufsc.br/index.php/revemat/article/viewFile/19811322.2009v4n1p39/1215.

Acesso em: 27 out. 2016.

\section{SOBRE OS AUTORES:}

\section{Daniela Zanardo Rossetto}

Mestre em Ensino e Processos Formativos, Universidade Estadual Paulista (UNESP). Membro do Grupo de Pesquisa Formação de Professores e Ensino de Matemática da UNESP de Ilha Solteira. Correio eletrônico: dzanardorossetto@gmail.com

(iD https://orcid.org/0000-0001-6635-6964

\section{Inocêncio Fernandes Balieiro Filho}

Doutor em Educação Matemática, Universidade Estadual Paulista (UNESP). Professor do Departamento de Matemática da UNESP. Docente do Programa de Pós-Graduação em Ensino e Processos Formativos da UNESP. Membro do Grupo de Pesquisa Formação de Professores e Ensino de Matemática da UNESP. Correio eletrônico: inocencio.balieiro@ unesp.br (iD) https://orcid.org/0000-0003-4012-959X 